\title{
PENERAPAN ANIMASI INTERAKTIF DALAM PENGENALAN AKSARA SUNDA
}

\author{
Siti Maria Holida, Tuti Alawiyah, Herlan Sutisna \\ Manajemen Informatika \\ AMIK BSI Tasikmalaya \\ Jalan Tanuwijaya No. 4 Empang Sari - Tawang, Tasikmalaya \\ sitimariaholida@gmail.com, tuti.tah@bsi.ac.id, herlan.her@bsi.ac.id
}

\begin{abstract}
Sundanese script is the work of Sundanese orthography to be maintained and preserved, because the Sundanese script is a cultural heritage that is priceless. Socialization of Sundanese script is very minimal done, although West Java government has to take legal actions in the form of regional regulations No. 5 of 2003 and the Governor's Decree no. 434 / SK.614 / dis-pk / 1999. Along with the increasing sophistication of technology, the use of interactive animations introduction Sundanese script can be used to promote literacy by explaining the meaning of the Sundanese, Sundanese script, history Sundanese script, how to write Sundanese script, as well as Sundanese script puzzle games as testing and entertainment. Application of interactive animation is the best solution which is very helpful in Sundanese script publicizes to the community, especially people of sundanese to be more interested in learning Sundanese script that became cultural heritage.
\end{abstract}

Keywords : Interactive Animation, Script Sundanese

\begin{abstract}
Abstrak - Aksara Sunda merupakan hasil karya ortografi masyarakat Sunda yang harus dipelihara dan dilestarikan, karena aksara Sunda adalah warisan budaya yang tidak ternilai harganya. Sosialisasi aksara Sunda masih sangat minim dilakukan, meskipun pemerintah Jawa barat sudah melakukan upaya hukum dalam bentuk Peraturan daerah (Perda) no.5 tahun 2003 dan Surat Keputusan Gubernur no. 434/SK.614/dis-pk/1999. Seiring dengan semakin canggihnya tekhnologi, penggunaan animasi interaktif pengenalan aksara sunda dapat digunakan untuk mensosialisasikan aksara Sunda dengan menjelaskan mengenai pengertian aksara Sunda, sejarah aksara Sunda, cara penulisan aksara Sunda, serta game puzzle aksara Sunda sebagai pengujian dan hiburannya. Penerapan animasi interaktif merupakan solusi terbaik yang sangat membantu dalam mensosialisakan aksara Sunda kepada masyarakat khususnya masyarakat Sunda agar lebih berminat mempelajari aksara Sunda yang menjadi warisan budaya.
\end{abstract}

Kata Kunci : Animasi Interaktif, Aksara Sunda

\section{PENDAHULUAN}

Aksara Sunda adalah salah satu unsur budaya yang harus dilestarikan khususnya oleh masyarakat Jawa Barat, karena aksara Sunda merupakan aksara tradisi hasil karya ortografi masyarakat Sunda melalui perjalanannya sejak abad yang lalu hingga saat ini. Untuk meningkatkan usaha pemeliharaan dan pemberdayaan aksara Sunda khas di Jawa Barat maka tepat kiranya jika dibuat alat informasi interaktif untuk memperkenalkan aksara Sunda kepada suluruh masyarakat.

Seiring semakin canggihnya teknologi, maka pelestarian aksara Sunda sebagai warisan budaya bisa dibuat dengan membuat animasi interaktif. Salah satu perangkat lunak pembuat animasi interaktif adalah flash. Flash adalah sebuah program yang diciptakan untuk membuat animasi berupa teks maupun gambar mulai dari yang sederhana hingga yang kompleks. Penggunaan Animasi interaktif memperkenalkan 
aksara Sunda tentu sangat berperan penting untuk mensosialisasikan aksara Sunda, karena dengan animasi interaktif, masyarakat akan lebih tertarik dan lebih mudah memahami dalam mempelajari penulisan aksara Sunda. Salah satu perangkat lunak pembuat animasi yang cukup populer saat ini adalah Adobe Flash.

Berdasarkan upaya hukum pemerintah Jawa Barat yang telah diuraikan, untuk memelihara bahasa dan aksara maka dibuatlah sebuah program animasi Interaktif sebagai media bantu untuk memperkenalkan aksara Sunda kepada seluruh masyarakat.

\section{KAJIAN LITERATUR}

Animasi berasal dari kata "Animation" yang dalam bahasa inggris "to animate" yang berarti mengerakan. Jadi animasi dapat diartikan sebagai mengerakan sesuatu (gambar atau obyek) yang diam. Sejarah animasi dimulai dari jaman purba, dengan ditemukannya lukisanlukisan pada dinding goa di Spanyol yang menggambarkan "gerak" dari binatang-binatang. Pada 4000 tahun yang lalu bangsa Mesir juga mencoba menghidupkan satu peristiwa dengan gambar-gambar yang dibuat berurutan pada dinding.

Sejak menyadari bahwa gambar bisa dipakai sebagai alternatif media komunikasi, timbul keinginan menghidupkan lambanglambang tersebut menjadi cermin ekspresi kebudayaan. Terbukti dengan ditemukannya berbagai artefak pada peradaban Mesir Kuno 2000 Sebelum Masehi. Salah satunya adalah beberapa panel yang menggambarkan aksi dua pegulat dalam berbagai pose. Animasi sendiri tidak akan pernah berkembang tanpa ditemukannya prinsip dasar dari karakter mata manusia yaitu: persistance of vision (pola penglihatan yang teratur). Paul Roget, Joseph Plateau dan Pierre Desvigenes, melalui peralatan optik yang mereka ciptakan, berhasil membuktikan bahwa mata manusia cenderung menangkap urutan gambar-gambar pada tenggang waktu tertentu sebagai suatu pola. Dalam perkembangannya animasi secara umum bisa didefinisikan sebagai suatu sequence gambar yang di-ekspos pada tenggang waktu tertentu sehingga tercipta sebuah ilusi gambar bergerak.

Menurut Syarif (2008:2) Pengertian Animasi adalah "serangkaian gambar dan secara in beetwin dengan jumlah yang banyak, bila kita proyeksikan akan terlihat seolah-olah hidup (bergerak). Seperti yang pernah kita lihat film- film kartun di televisi maupun di layar lebar. Jadi animasi bisa kita simpulkan dengan menghidupkan benda diam yang diproyeksikan menjadi bergerak". Menurut Reiber dalam Munir (2012:317) "Animasi berasal dari bahasa latin yaitu "anima" yang berarti jiwa, hidup, semangat". Secara umum animasi merupakan suatu kegiatan menghidupkan, menggerakan benda mati. Sedangkan pengertian Interaktif menurut Munir (2012:110) "terkait dengan komunikasi dua arah atau lebih dari komponenkomponen komunikasi. Komponen komunikasi adalah hubungan antara manusia (sebagai user/pengguna produk) dan komputer (software/aplikasi/produk dalam format file tertentu, biasanya dalam bentuk CD)".

Berdasarkan pengertian animasi dan interaktif tersebut, maka animasi interaktif adalah suatu tampilan animasi yang dirancang oleh desainer agar tampilannya memenuhi fungsi menginformasikan pesan dan memiliki interaktifitas kepada penggunanya (user).

Berdasarkan Peraturan Daerah (Perda) Nomor 6 Tahun 1996, yang dikeluarkan oleh Pemerintah Daerah Tingkat I Propinsi Jawa Barat mengenai rumusan tentang aksara Sunda. Rumusan dimaksud berbunyi, "Aksara Sunda adalah sistem ortografi hasil kreasi masyarakat Jawa Barat yang meliputi aksara dan sistem pengaksaraan untuk menuliskan bahasa Sunda" (Pasal 1 nomor k.).

Aksara Sunda berjumlah 32 buah yang terdiri atas 7 aksara swara 'vokal mandiri' ( $a, e ́, i$, $o, \quad u, e$, dan eu) dan 23 aksara ngalagena 'konsonan' (ka-ga-nga, ca-ja-nya, ta-da-na, paba-ma, ya-ra-la, wa-sa-ha, fa-va-qa-xa-za,). Aksara swara adalah tulisan yang melambangkan bunyi fonem vokal mandiri yang dapat berperan sebagai sebuah suku kata yang bisa menempati posisi awal, tengah maupun akhir sebuah kata. Sedangkan aksara ngalagena adalah tulisan yang secara silabis dianggap dapat melambangkan bunyi fonem konsonan dan dapat berperan sebagai sebuah kata maupun suku kata yang bisa menempati posisi awal, tengah maupun akhir sebuah kata. Jadi aksara Sunda ini bersifat silabik, yakni tulisan yang dapat mewakili sebuah kata dan suku kata.

\section{METODE PENELITIAN}

Metode penelitian yang digunakan untuk mengumpulkan data dalam pembuata animasi interaktif aksara Sunda ini menggunakan studi kepustakaan melalui jurnal, situs internet, serta buku-buku yang berkaitan dengan aksara sunda 
dan animasi interaktif. Sedangkan dalam pengembangan perangkat lunaknya dibagi kedalam beberapa tahap, diantaranya:

1. Analisa Kebutuhan

Tahapan ini sangat menekankan pada masalah pengumpulan kebutuhan pengguna pada tingkatan sistem dengan menentukan konsep sistem beserta antar muka yang menghubungkannya dengan lingkungan sekitar. Hasilnya berupa spesifikasi sistem.

2. Perancangan Sistem dan Perangkat Lunak Proses perancangan sistem ini difokuskan pada Storyboard dan antar muka

3. Implementasi dan Pengujian Unit

Pada tahap ini, perancangan perangkat lunak direalisasikan sebagai serangkaian program atau unit program. Kemudian pengujian unit melibatkan verifikasi bahwa setiap unit program telah memenuhi spesifikasinya.

\section{PEMBAHASAN}

\section{Aksara Sunda}

Jenis Aksara Sunda terdiri dari:

1. Aksara Swara

Aksara swara adalah aksara yang secara silabis memiliki harkat bunyi vokal yang dalam sistem aksara Sunda Kuno berjumlah lima buah. Ada tiga buah aksara swara yang masing-masing memiliki dua lambang, yaitu /a/, lé/, dan /i/. Ketiga varian lambang aksara masing-masing tersebut dalam penggunaannya sering dipertukarkan secara bebas dengan nilai harkat bunyi yang tetap. Hal tersebut adalah sebagai berikut:

$$
\begin{aligned}
& a=(3 \quad \text { é }=(Z \quad i=L \quad 0=7 n
\end{aligned}
$$

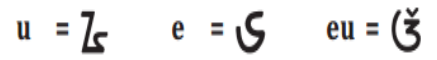

\section{Gambar 1} Aksara Swara

\section{Aksara Ngalagena}

Aksara ngalagena adalah lambang-lambang bunyi yang dapat dipandang sebagai fonem konsonan yang secara silabis mengandung bunyi vokal /a/. Jumlah aksara ngalagena ini ada dua puluh tiga jenis yang susunannya disesuaikan dengan sistem kedudukan alatalat ucap (artikulasi-atikulator), seperti guttural 'kerongkongan', palatal 'langitlangit', lingual 'lidah', dental 'gigi', dan labial 'bibir'. Hal dimaksud adalah sebagai berikut:

\begin{tabular}{|c|c|c|c|}
\hline $\mathrm{ka}=77$ & $\mathbf{g a}=\mathbf{Z}$ & nga & $=\mathbf{Z}$ \\
\hline ca $=Z$ & $\mathbf{j a}=Z_{n} \mathbf{l}$ & nya & $=\mathbf{Z} \boldsymbol{D}$ \\
\hline $\mathbf{a}=\mathbf{z}$ & $\mathbf{d a}=\overline{L a}$ & na & $=\mathbf{Z}$ \\
\hline $\mathbf{p a}=\mathbf{Z}$ & $\mathbf{b a}=\Delta \nabla$ & $\mathbf{m a}$ & $=\boldsymbol{\nabla}$ \\
\hline ya $=\mathrm{ZN}$ & $\mathbf{r a}=\overline{7}$ & $\mathbf{1 a}$ & $=N$ \\
\hline$w a=G$ & sa $=77$ & ha & $=2 \pi$ \\
\hline $\mathbf{f a}=\mathbf{Z}$ & $\mathbf{q a}=m$ & va & $=L$ \\
\hline $\mathbf{x a}=\not 7$ & $\mathbf{z a}=Z_{n}$ & & \\
\hline
\end{tabular}

Gambar 2

Aksara Ngalagena

3. Rarangkén Aksara Sunda

Lambang Rarangkén aksara Sunda terdiri dari 13 buah yang cara penulisannya ditempatkan sebagai berikut:

Tabel 1

Macam-macam Rarangkén

\begin{tabular}{|c|c|c|c|}
\hline No & $\begin{array}{l}\text { Lambang } \\
\text { Rarangkén }\end{array}$ & $\begin{array}{c}\text { Nama } \\
\text { Rarangkén }\end{array}$ & $\begin{array}{c}\text { Fungsi } \\
\text { Rarangkén }\end{array}$ \\
\hline 1. & & panghulu & $\begin{array}{l}\text { mengubah bunyi } \\
\text { vokal aksara } \\
\text { dasar /a/ menjadi } \\
\text { /i/ }\end{array}$ \\
\hline 2. & & pamepet & $\begin{array}{l}\text { mengubah bunyi } \\
\text { vokal aksara } \\
\text { dasar /a/ menjadi } \\
\text { le/ }\end{array}$ \\
\hline 3. & & paneuleung & $\begin{array}{l}\text { mengubah bunyi } \\
\text { vokal aksara } \\
\text { dasar /a/ menjadi } \\
\text { /eu/ }\end{array}$ \\
\hline 4. & & panglayar & $\begin{array}{l}\text { menambah } \\
\text { konsonan } \quad /+\mathrm{r} / \\
\text { pada } \\
\text { akhir aksara dasar }\end{array}$ \\
\hline 5. & & panyecek & $\begin{array}{l}\text { menambah } \\
\text { konsonan /+ng/ } \\
\text { pada akhir aksara } \\
\text { dasar }\end{array}$ \\
\hline 6. & 7 & panyuku & $\begin{array}{lr}\text { mengubah bunyi } \\
\text { vokal aksara } \\
\text { dasar /a/ menjadi } \\
\text { /u/ }\end{array}$ \\
\hline 7. & & panyakra & $\begin{array}{l}\text { menambah bunyi } \\
\text { aksara /+ra/ pada } \\
\text { aksara dasar yang } \\
\text { didekatinya, dan } \\
\text { bisa disesuaikan } \\
\text { dengan tanda } \\
\text { vokalisasi pada } \\
\text { aksara dasarnya }\end{array}$ \\
\hline 8. & $\boldsymbol{n}$ & panyiku & $\begin{array}{l}\text { menambah bunyi } \\
\text { aksara /+la/ pada } \\
\text { aksara dasar yang } \\
\text { didekatinya, dan } \\
\text { bisa disesuaikan } \\
\text { dengan tanda } \\
\text { vokalisasi pada } \\
\text { aksara dasarnya }\end{array}$ \\
\hline
\end{tabular}


Lanjutan Tabel 1

Macam-macam Rarangkén

\begin{tabular}{|c|c|c|c|}
\hline No & $\begin{array}{l}\text { Lambang } \\
\text { Rarangkén }\end{array}$ & $\begin{array}{c}\text { Nama } \\
\text { Rarangké } \\
n\end{array}$ & Fungsi Rarangkén \\
\hline 9. & & panéléng & $\begin{array}{ll}\text { mengubah } & \text { bunyi } \\
\text { vokal aksara } & \text { dasar } \\
\text { /a/ } & \text { yang } \\
\text { didahuluinya } & \\
\text { menjadi /é/ } & \end{array}$ \\
\hline 10. & & panolong & $\begin{array}{ll}\text { mengubah bunyi } \\
\text { vokal aksara dasar } \\
\text { /a/ } & \text { yang } \\
\text { mendahuluinya } \\
\text { menjadi /o/ }\end{array}$ \\
\hline 11. & & $\begin{array}{c}\text { pamingka } \\
l\end{array}$ & $\begin{array}{lr}\text { menambah } & \text { bunyi } \\
\text { /+ya/ pada } & \text { aksara } \\
\text { dasar } & \text { yang } \\
\text { didekatinya, } & \text { dan } \\
\text { bisa disesuaikan } \\
\text { dengan } & \text { tanda } \\
\text { vokalisasi } & \text { pada } \\
\text { aksara dasarnya. }\end{array}$ \\
\hline 12. & & $\begin{array}{c}\text { pangwisa } \\
d\end{array}$ & $\begin{array}{l}\text { menambah } \\
\text { konsonan /+h/ pada } \\
\text { akhir aksara dasar }\end{array}$ \\
\hline 13. & & pamaéh & $\begin{array}{l}\text { menghilangkan } \\
\text { bunyi vokal pada } \\
\text { aksara dasar yang } \\
\text { mendahuluinya pada } \\
\text { aksara dasar yang } \\
\text { mendahuluinya }\end{array}$ \\
\hline
\end{tabular}

4. Angka Aksara Sunda

Sistem tata tulis aksara Sunda dilengkapi pula dengan lambang angka-angka. Penulisan lambang angka puluhan, ratusan, dan seterusnya ditulis berderet dari "kiri ke kanan", seperti halnya dalam sistem angka Arab. Beberapa lambang angka Sunda bentuknya ada yang mirip dengan lambang aksara sehingga untuk menuliskan (deretan) lambang angka harus diapit dengan garis vertikal yang lebih tinggi dari lambang angka. Lambang angka-angka yang dimaksud adalah:

$\begin{array}{llll}1=Z & 2=Z & 3=Z \\ 4=7 & 5=Z & 6=k \\ 7=J I & 8=J & 9=E \\ 0=0 & & \end{array}$

Gambar 3

Angka Aksara Sunda
Rancangan Storyboard

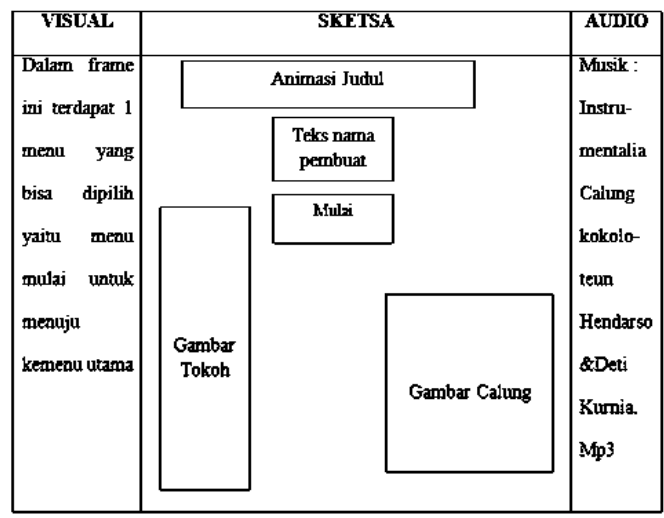

Gambar 4

Storyboard Judul

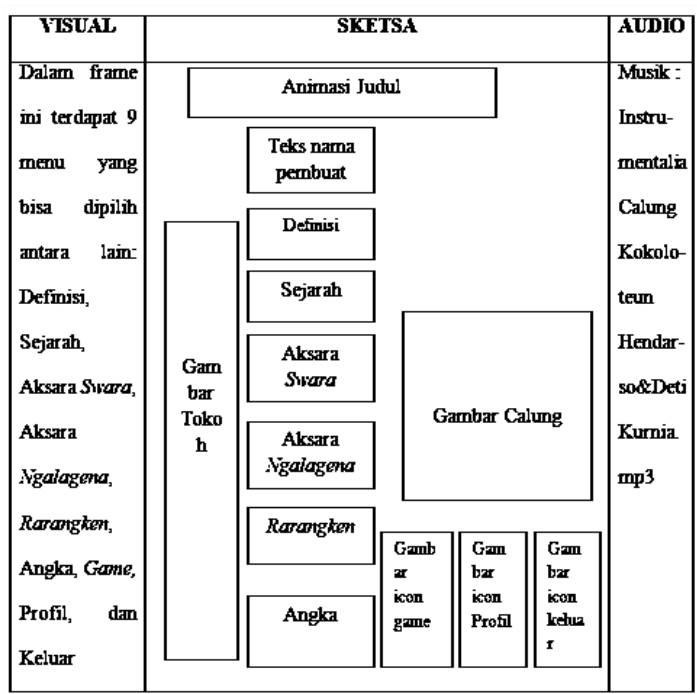

Gambar 5

Storyboard Menu Utama

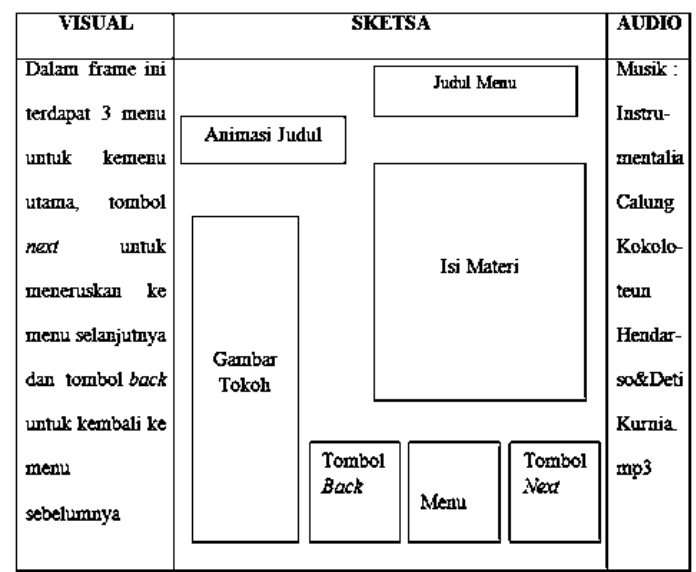

Gambar 6

Storyboard Menu Definisi Aksara Sunda 


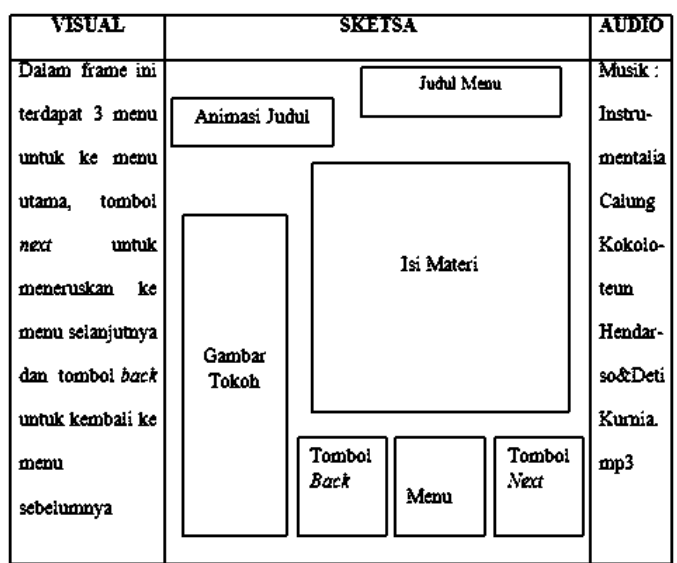

Gambar 7

Storyboard Menu Sejarah Aksara Sunda

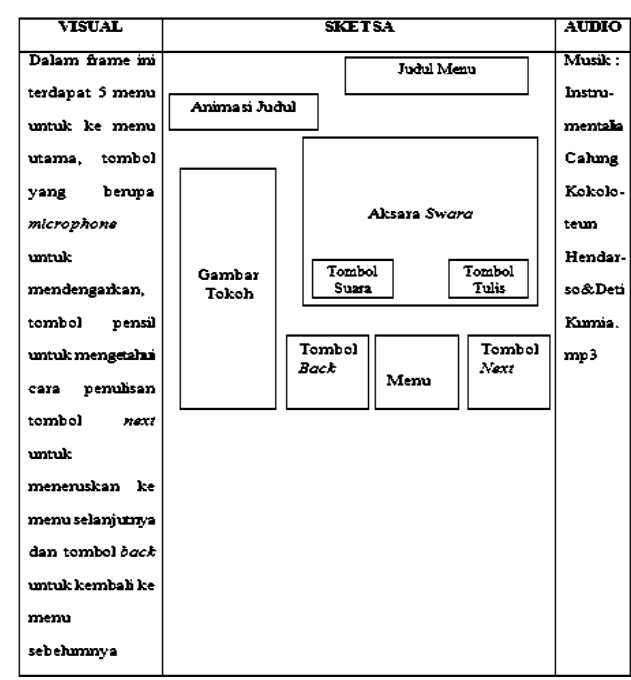

Gambar 8

Storyboard Menu Aksara Swara

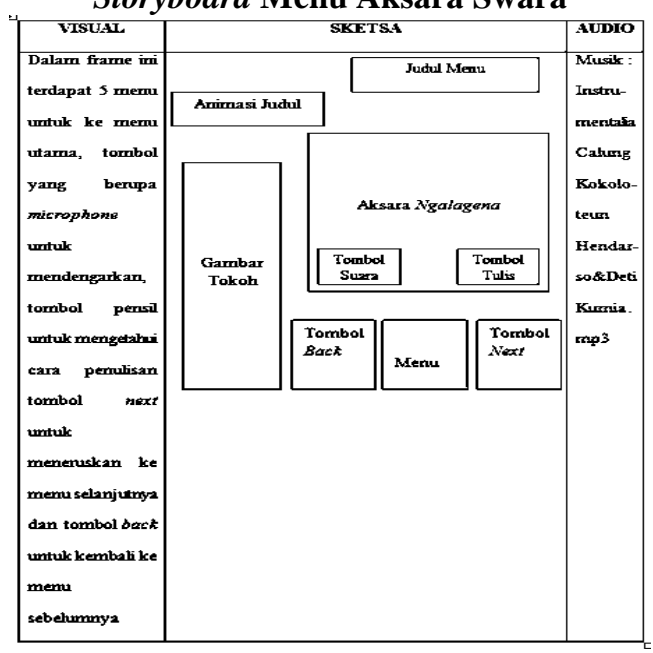

Gambar 9

Storyboard Menu Aksara Ngalagena

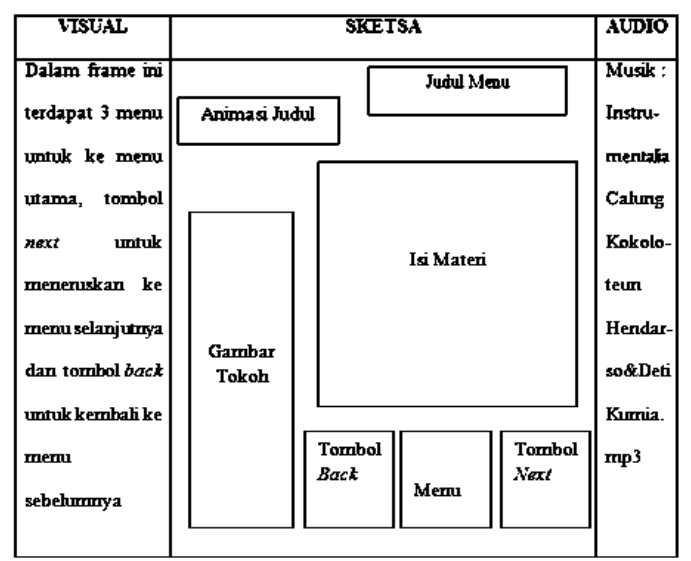

Gambar 10

Storyboard Menu Rarangkén Aksara Sunda

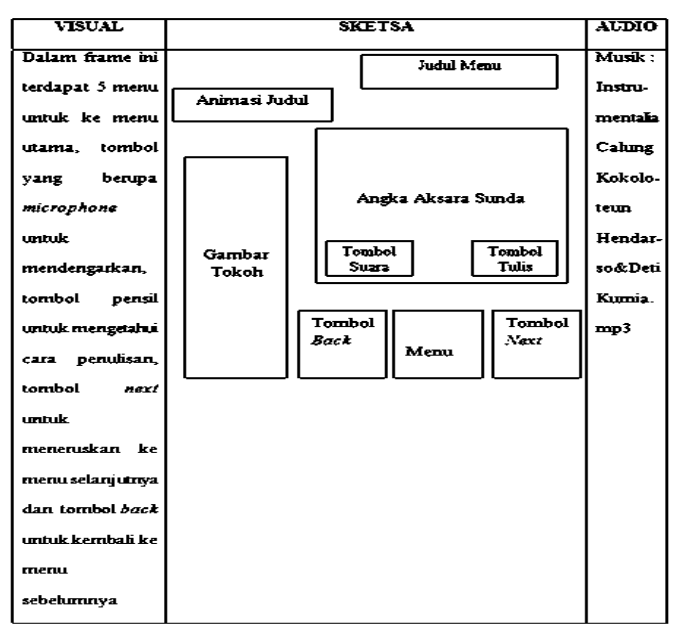

Gambar 11

Storyboard Menu Angka Aksara Sunda

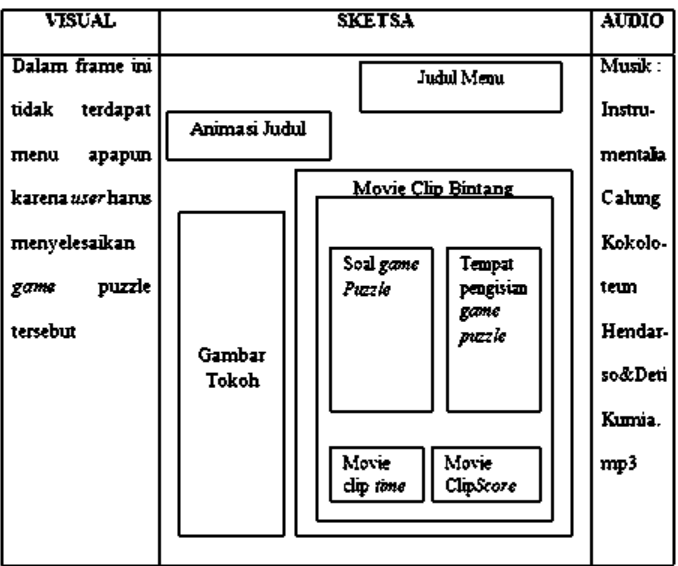

Gambar 12

Storyboard Permainan/ Game Puzzle Aksara Sunda 


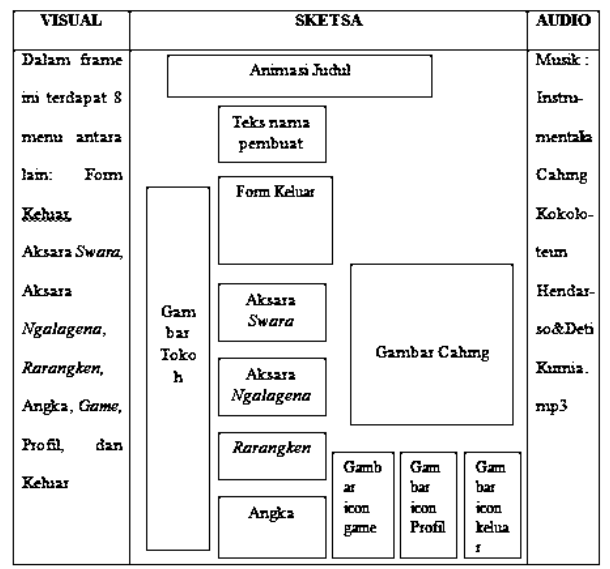

Gambar 13

Storyboard Menu Keluar

\section{Rancangan Antarmuka}

1. Tampilan Judul

Tampilan ini berisi tentang judul program animasi yang sedang dimainkan yang berisi satu menu untuk memulai.

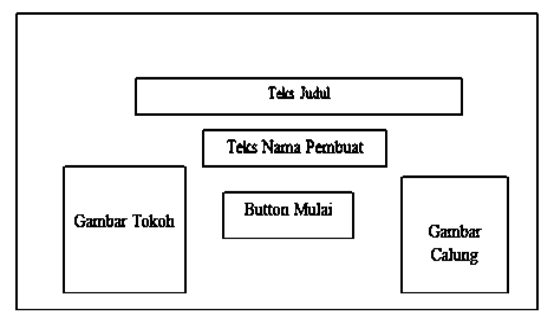

Gambar 14

Tampilan Judul

2. Tampilan Menu Utama

Tampilan menu utama berisi 8 tombol menu dan 1 tombol navigasi untuk keluar, diantaranya definisi aksara Sunda, sejarah aksara Sunda, aksara swara, aksara ngalagena, rarangken, angka, game puzzle aksara Sunda.

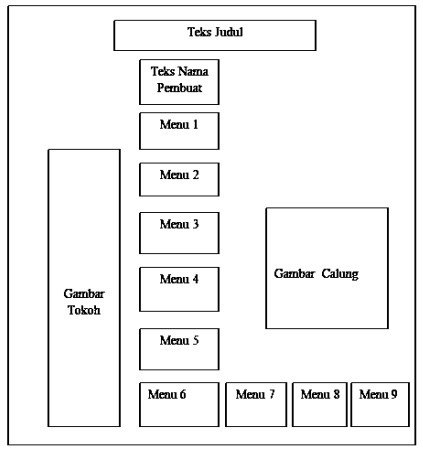

Gambar 15

Tampilan Menu Utama
3. Tampilan Menu Definisi

Tampilan menu definisi berisi 3 tombol menu untuk ke menu utama, tombol next untuk meneruskan ke menu selanjutnya dan tombol back untuk kembali ke menu sebelumnya.

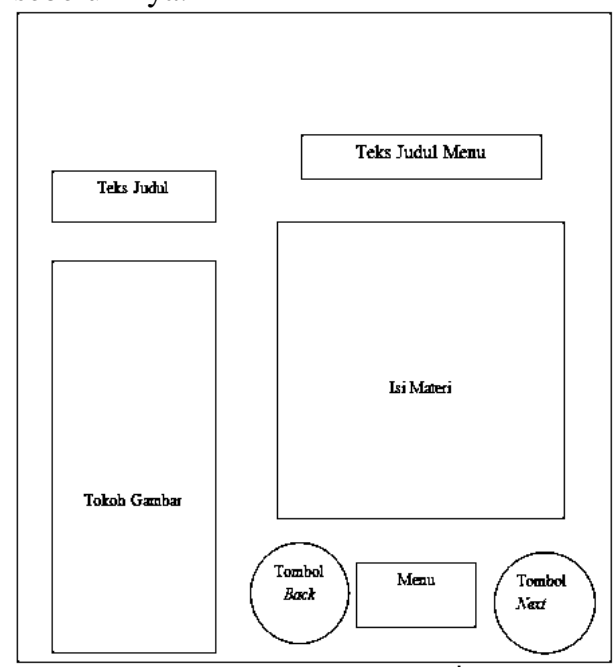

Gambar 16

Tampilan Menu Definisi

4. Tampilan Menu Sejarah

Tampilan menu sejarah berisi 3 tombol menu untuk ke menu utama, tombol next untuk meneruskan ke menu selanjutnya dan tombol back untuk kembali ke menu sebelumnya.

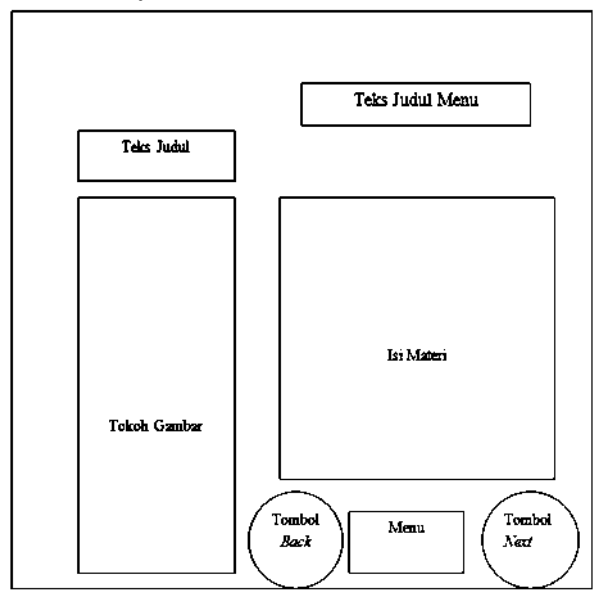

Gambar 17

Tampilan Menu Sejarah

5. Tampilan Menu Aksara Swara

Tampilan menu aksara swara berisi 5 tombol menu untuk ke menu utama, tombol suara yang berupa microphone untuk mendengarkan, tombol tulis yang berupa pensil untuk mengetahui cara penulisan, 
tombol next untuk meneruskan ke menu selanjutnya dan tombol back untuk kembali ke menu sebelumnya.

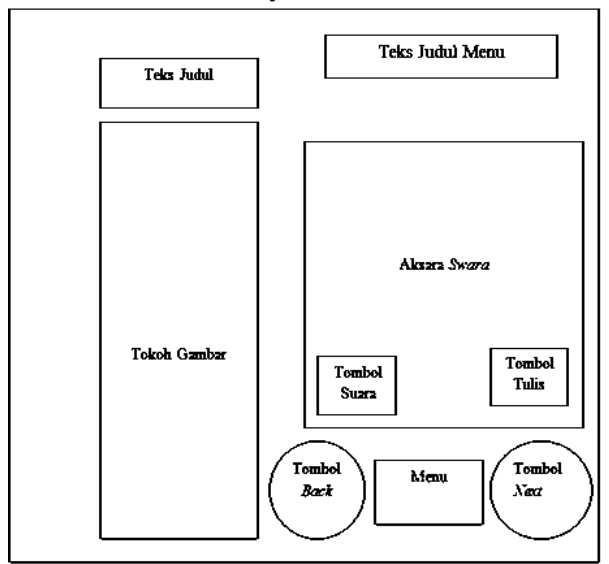

Gambar 18

Tampilan Menu Aksara Swara

6. Tampilan Menu Aksara Ngalagena Tampilan menu aksara ngalagena berisi 5 tombol menu untuk ke menu utama, tombol suara yang berupa microphone untuk mendengarkan, tombol tulis yang berupa pensil untuk mengetahui cara penulisan, tombol next untuk meneruskan ke menu selanjutnya dan tombol back untuk kembali ke menu sebelumnya.

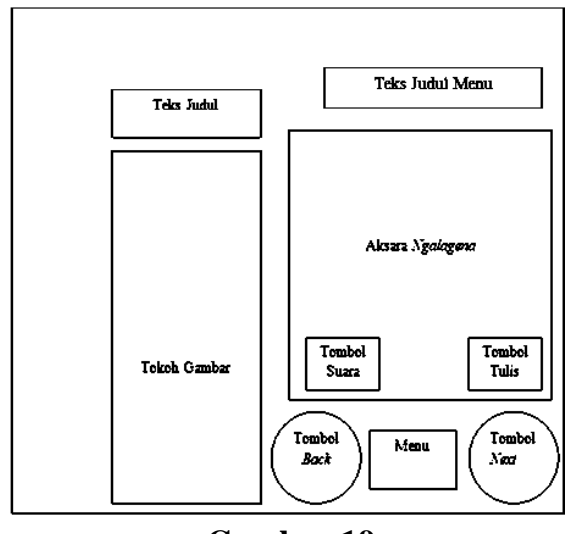

Gambar 19

Tampilan Menu Aksara Ngalagena

7. Tampilan Menu Rarangkén

Tampilan menu rarangkén berisi 3 tombol menu untuk ke menu utama, tombol next untuk meneruskan ke menu selanjutnya dan tombol back untuk kembali ke menu sebelumnya.

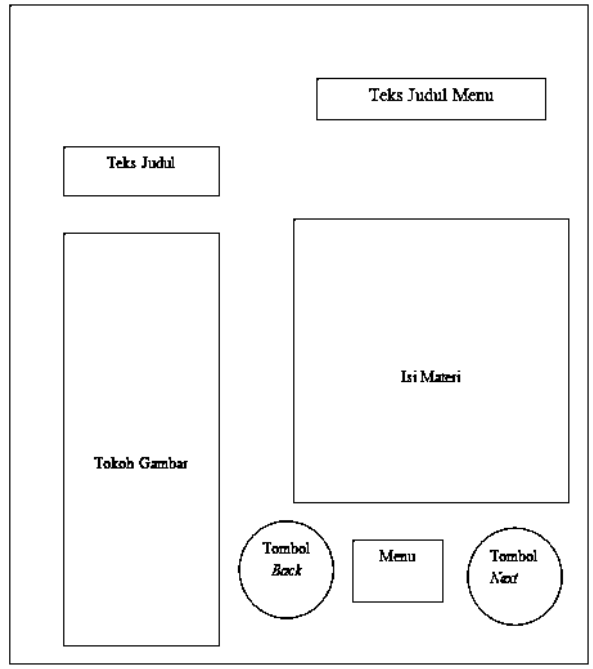

\section{Gambar 20}

Tampilan Menu Rarangkén

8. Tampilan Menu Angka Aksara Sunda Tampilan menu angka aksara Sunda berisi 5 tombol menu untuk ke menu utama, tombol suara yang berupa microphone untuk mendengarkan, tombol tulis yang berupa pensil untuk mengetahui cara penulisan, tombol next untuk meneruskan ke menu selanjutnya dan tombol back untuk kembali ke menu sebelumnya.

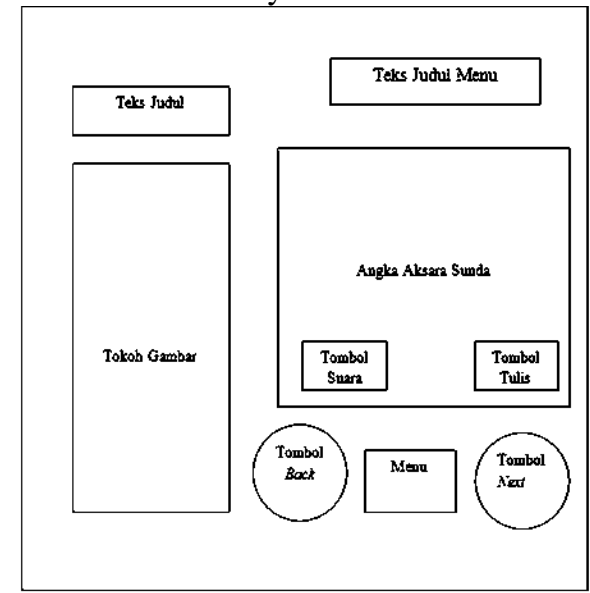

Gambar 21

Tampilan Menu Angka Aksara Sunda

9. Tampilan Menu Permainan/Game Fuzzle Aksara Sunda

Tampilan menu game puzzle aksara Sunda tidak terdapat menu apapun karena user harus menyelesaikan game puzzle tersebut. 


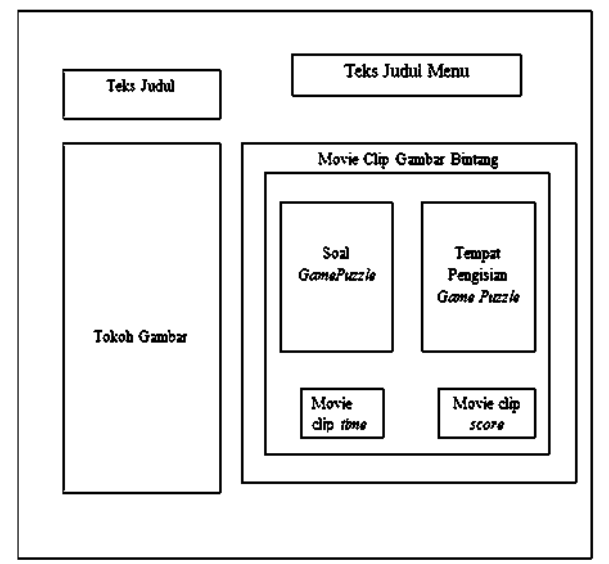

Gambar 22

Tampilan Menu Permainan/Game Fuzzle Aksara Sunda

10. Tampilan Menu Keluar

Tampilan menu keluar berisi 8 menu antara lain: form keluar, aksara swara, aksara ngalagena, rarangken, angka, game, profil, dan keluar.

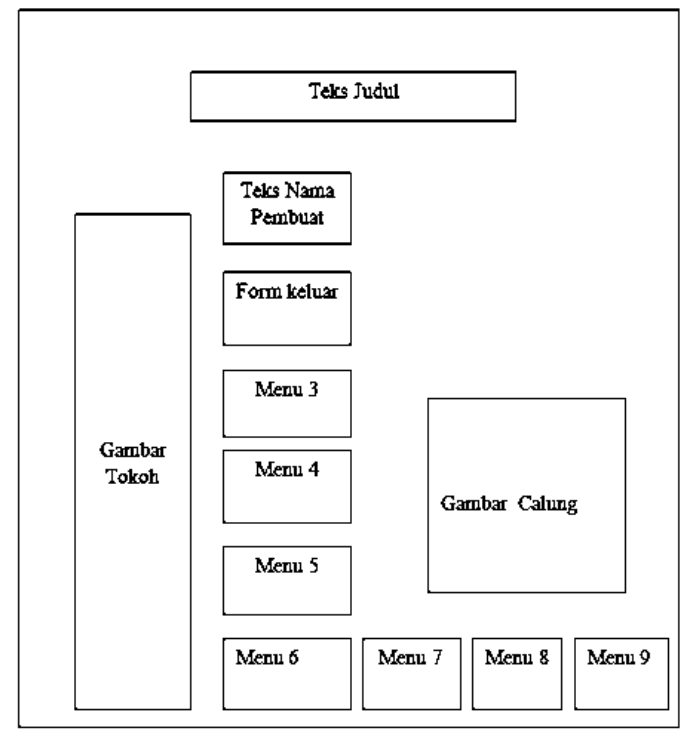

Gambar 23

Tampilan Menu Keluar
1. Implementasi

a. Tampilan Judul

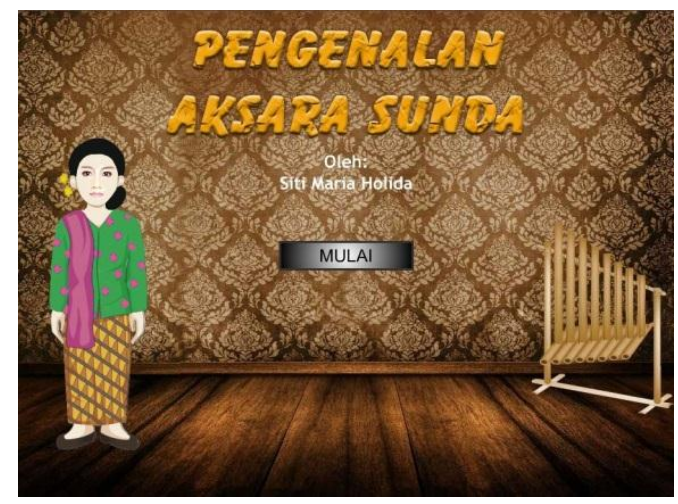

Gambar 24

Tampilan Judul

b. Tampilan Menu Utama

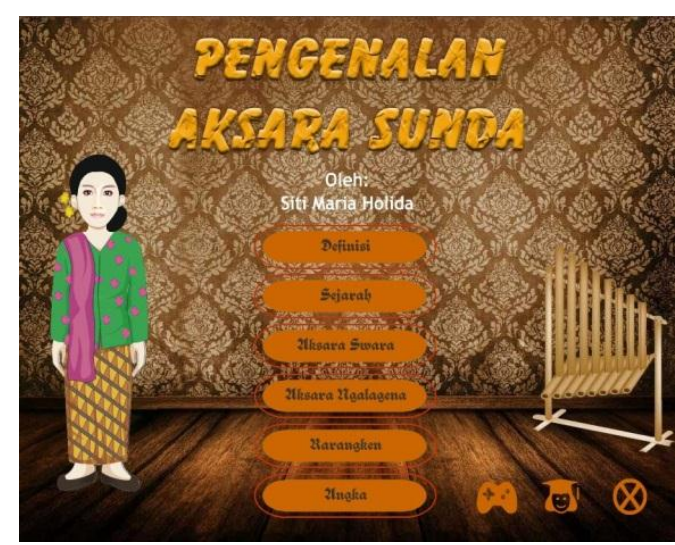

Gambar 25

Tampilan Menu Utama

c. Tampilan Menu Definisi

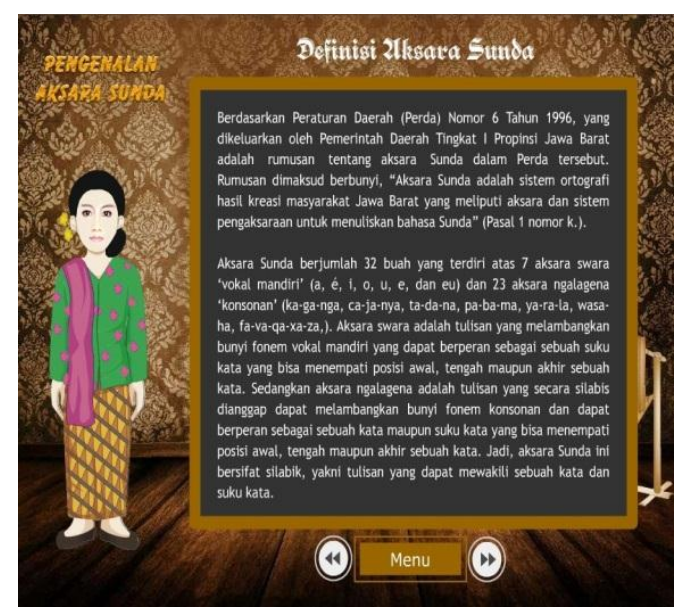

Gambar 26

Tampilan Menu Definisi 
d. Tampilan Menu Sejarah

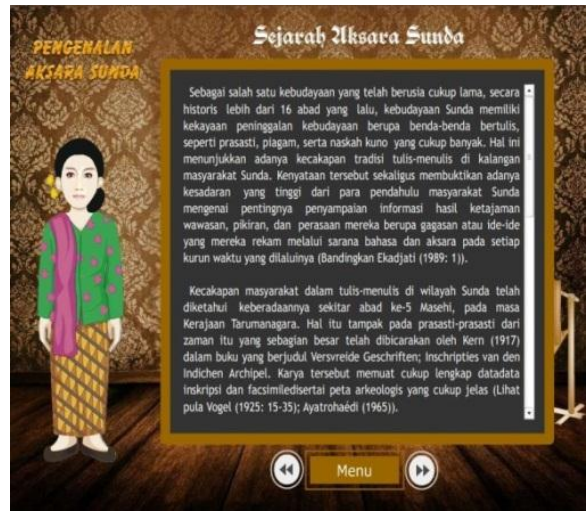

Gambar 27

Tampilan Menu Sejarah

e. Tampilan Menu Aksara Swara

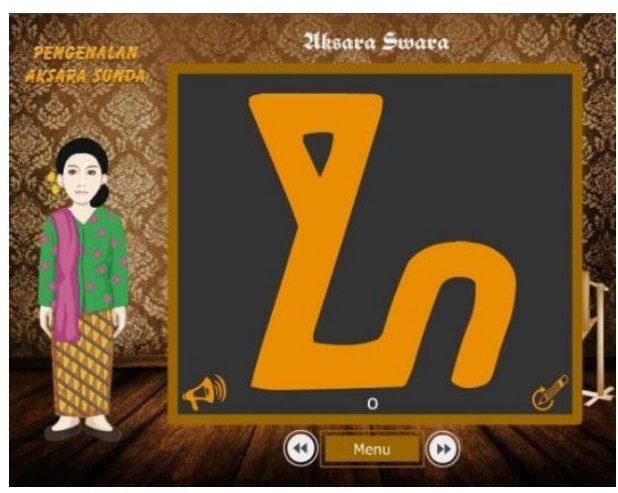

Gambar 28

Tampilan Menu Aksara Swara

f. Tampilan Menu Aksara Ngalagena

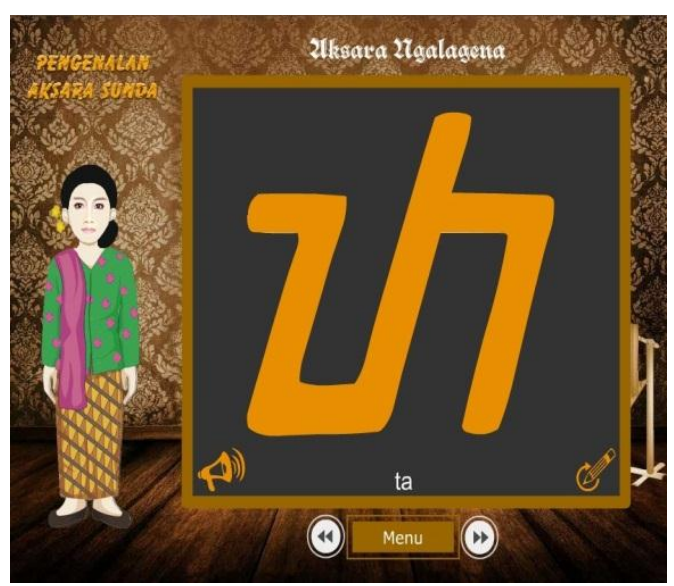

Gambar 29

Tampilan Menu Aksara Ngalagena

\section{g. Tampilan Menu Rarangkén}

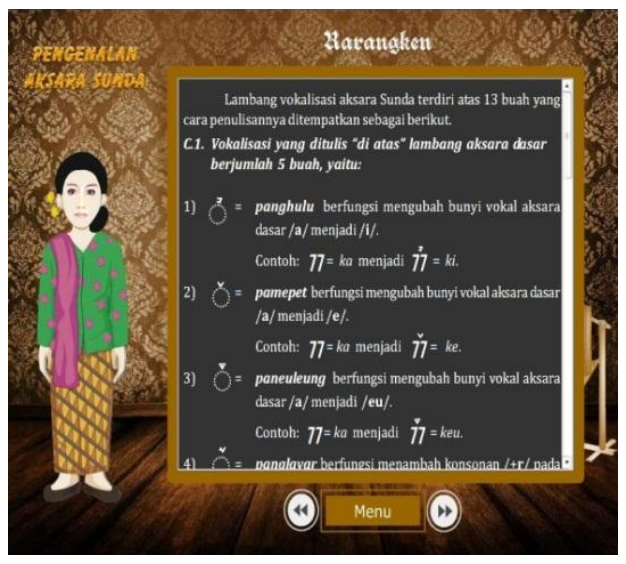

Gambar 30

Tampilan Menu Rarangkén

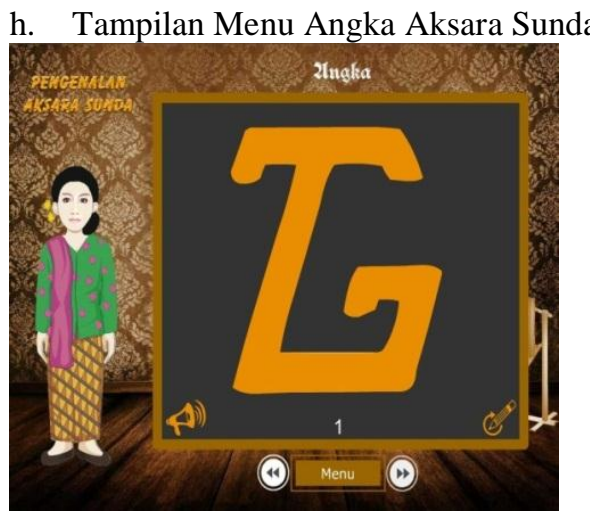

Gambar 31

Tampilan Menu Angka Aksara Sunda

i. Tampilan Menu Permainan/Game Puzzle Aksara Sunda

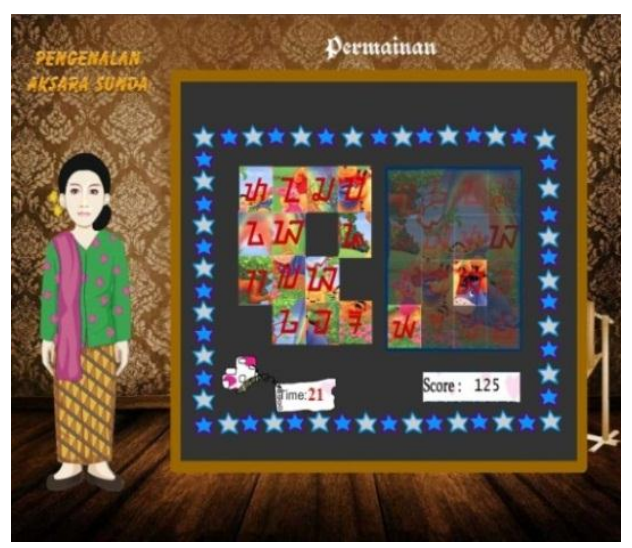

Gambar 32

Tampilan Menu Permainan/Game Puzzle Aksara Sunda 
j. Tampilan Menu Keluar

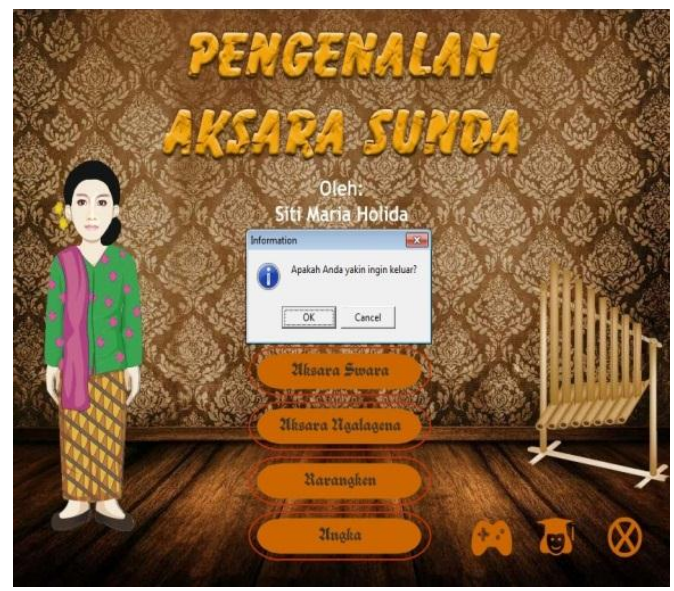

Gambar 33

Tampilan Menu Keluar

2. Pengujian Unit

Tabel IV.2. Hasil Pengujian Black Box Testing Halaman Judul

\begin{tabular}{|c|c|c|c|}
\hline Input/Event & Proses & $\begin{array}{c}\text { Output } \\
\text { Nest Stage }\end{array}$ & $\begin{array}{c}\text { Hasil } \\
\text { Pengujian }\end{array}$ \\
\hline Tombol "Mulai" & on & $\begin{array}{c}\text { Menu } \\
\text { Utama }\end{array}$ & Sesuai \\
\hline
\end{tabular}

Tabel 2

Hasil Pengujian

Black Box Testing Halaman Menu Utama

\begin{tabular}{|c|c|c|c|}
\hline $\begin{array}{c}\text { Inpo } t / E v e \\
n t\end{array}$ & Proses & $\begin{array}{c}\text { Output/ } \\
\text { Next } \\
\text { Slage }\end{array}$ & $\begin{array}{c}\text { Hasil } \\
\text { Penguj } \\
\text { ian }\end{array}$ \\
\hline \begin{tabular}{|c|} 
Tombol \\
"Definisi"
\end{tabular} & on (release) \{gotoAndStop("Definisi"); & $\begin{array}{c}\text { Menu } \\
\text { Definisi }\end{array}$ & Sesuai \\
\hline \begin{tabular}{|c|} 
Tombol \\
"Sejarah" \\
\end{tabular} & on (release) $\{$ gotoAndStop("Sejarah"); $\}$ & $\begin{array}{c}\text { Menu } \\
\text { Sejarah }\end{array}$ & Sesuai \\
\hline \begin{tabular}{|c|} 
Tombol \\
"Swara" \\
\end{tabular} & on(release) $\{$ gotoAndStop("Swara"); & $\begin{array}{l}\text { Menu } \\
\text { Swara }\end{array}$ & Sessuai \\
\hline \begin{tabular}{|c|}
$\begin{array}{c}\text { Tombol } \\
\text { "Ngalage } \\
\text { na" }\end{array}$ \\
\end{tabular} & on(release) \{gotoAndStop("Ngalagena"); & \begin{tabular}{|c|} 
Menu \\
Ngalagena
\end{tabular} & Sessuai \\
\hline 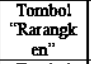 & on(release) \{gotoAndStop("Rarangken"); & $\begin{array}{c}\text { Menu } \\
\text { Rarangken }\end{array}$ & Sessuai \\
\hline \begin{tabular}{|c|} 
Tombol \\
"Angka" " \\
\end{tabular} & on(release) \{gotoAndStop("Angka"); & $\begin{array}{l}\text { Menu } \\
\text { Angka }\end{array}$ & Sesuai \\
\hline \begin{tabular}{|c|} 
Tombol \\
"Permaina \\
$\mathrm{n}$ "
\end{tabular} & on(release) $\{$ gotoAndStop("Permainan"); & $\begin{array}{c}\text { Menu } \\
\text { Permainan }\end{array}$ & Sensai \\
\hline \begin{tabular}{|l|} 
Tombol \\
"Profil" \\
\end{tabular} & on(release) $\{$ gotoAndStop("Profll"); & $\begin{array}{l}\text { Menu } \\
\text { Profil }\end{array}$ & Sesuai \\
\hline \begin{tabular}{|l|} 
Tombol \\
"Keluar"
\end{tabular} & $\begin{array}{l}\text { on(release)(mdm Application exit("ask","Apakah } \\
\text { Anda yakin ingin keluar?")\} Anda yakin ingin } \\
\text { keluar?")\} }\end{array}$ & $\begin{array}{l}\text { Menu } \\
\text { Keluar }\end{array}$ & Sesuai \\
\hline
\end{tabular}

Tabel 3

Hasil Pengujian

Black Box Testing Halaman Menu Definisi

\begin{tabular}{|c|c|c|c|}
\hline Inpat/Erent & Proses & $\begin{array}{c}\text { Outputy } \\
\text { Net Stage }\end{array}$ & $\begin{array}{c}\text { Hasil } \\
\text { Pengujiar }\end{array}$ \\
\hline Tombed "Back" & on (release) $\{$ prevFrame $0 ;\}$ & Sebelumnya & Sesuai \\
\hline Tambel "Menu" & $\begin{array}{c}\text { on } \\
\text { (release)(gotoAndStop("Menu"); }\end{array}$ & $\begin{array}{l}\text { Mepu } \\
\text { Utama }\end{array}$ & Sesuai \\
\hline Tombel "Naxt" & on (release) $\{$ nextFrame $0 ;\}$ & Selanjutrya & Sesuai \\
\hline
\end{tabular}

Tabel 4

Hasil Pengujian

Black Box Testing Halaman Menu Sejarah

\begin{tabular}{|c|c|c|c|}
\hline Inputzwent & Proses & $\begin{array}{l}\text { Outpul Naxt } \\
\text { Stage }\end{array}$ & $\begin{array}{c}\text { Fosil } \\
\text { Pengujian }\end{array}$ \\
\hline $\begin{array}{l}\text { Tombol } \\
\text { "Back" }\end{array}$ & on (release) $\{$ prevFrame $0 ;\}$ & Sebelumnya & Sesuai \\
\hline "Momber & $\begin{array}{l}\text { (release) } \text { (gon } \\
\text { on }\end{array}$ & Menu Utama & Sesuaj \\
\hline Tombel "Vex" & on (release), (nextFrame0;) & Seianjunya & Sesuaj \\
\hline
\end{tabular}

Tabel 5

Hasil Pengujian

Black Box Testing Halaman Menu Swara

\begin{tabular}{|c|c|c|c|}
\hline Input/Event & Proses & $\begin{array}{c}\text { Output } / \text { Next } \\
\text { Stage }\end{array}$ & $\begin{array}{c}\text { Fassil } \\
\text { Pengujian }\end{array}$ \\
\hline "Torabel & on(release)\{gotoAndPlay(51);\} & $\begin{array}{l}\text { mendengarkan } \\
\text { bunyi aksara } \\
\text { Swara }\end{array}$ & Sesuai \\
\hline $\begin{array}{l}\text { Torabel } \\
\text { "Tulis" }\end{array}$ & on(release) \{gotoAndPlay(1);\} & $\begin{array}{c}\text { melihat cara } \\
\text { penulisan } \\
\text { aksara Swara }\end{array}$ & Sesuai \\
\hline $\begin{array}{l}\text { Trabedl } \\
\text { "Back" }\end{array}$ & on (release) \{prevFrame 0 :\} & Sebelumnya & Sesuai \\
\hline $\begin{array}{l}\text { Trabkel } \\
\text { "Menu" }\end{array}$ & $\begin{array}{c}\text { on } \\
\text { (felease) \{gotoAndStop("Menu"); }\end{array}$ & Menu Utama & Sesuai \\
\hline Tented & on (release) \{nextFrame0:\} & Selanjutnya & Se्quai \\
\hline
\end{tabular}

Tabel 6

Hasil Pengujian Black Box Testing Halaman Menu Ngalagena

\begin{tabular}{|c|c|c|c|}
\hline Input/Event & Proses & $\begin{array}{l}\text { Output } / \text { Nact } \\
\text { Stage }\end{array}$ & $\begin{array}{c}\text { Hasil } \\
\text { Pengujian }\end{array}$ \\
\hline $\begin{array}{l}\text { Torabel } \\
\text { "Suara" }\end{array}$ & on(release) $\{$ gotoAndP1ay $(51) ;\}$ & $\begin{array}{l}\text { mendengarkan } \\
\text { bunyi aksara } \\
\text { Ngalagena }\end{array}$ & Sesuai \\
\hline $\begin{array}{l}\text { Temabel } \\
\text { "Tulis" }\end{array}$ & on(release) \{gotoAndPlay (1);\} & $\begin{array}{l}\text { Untuk melihat } \\
\text { cara penulisan } \\
\text { aksara } \\
\text { Ngalagena }\end{array}$ & Sesuzi \\
\hline $\begin{array}{l}\text { Ternbel } \\
\text { "Back' }\end{array}$ & on (release) $\{$ prevFrame 0 ;\} & Sebelumnya & Sesuria \\
\hline $\begin{array}{l}\text { Tombel } \\
\text { "Menu" }\end{array}$ & $\begin{array}{c}\text { on } \\
\text { (release) }\{\text { gotoAndStop("Menu"); }\end{array}$ & Menu Utama & Sesuai \\
\hline $\begin{array}{l}\text { Tembel } \\
\text { "Next" }\end{array}$ & on (release) $\{$ nextFrame 0 ;\} & Selanjumya & Sesuzi \\
\hline
\end{tabular}

Tabel 7

Hasil Pengujian Black Box Testing Halaman Menu Rarangkén

\begin{tabular}{|c|c|c|c|}
\hline Input/Event & Proses & $\begin{array}{c}\text { Output/Next } \\
\text { Stage }\end{array}$ & $\begin{array}{c}\text { Hasil } \\
\text { Pengujian }\end{array}$ \\
\hline $\begin{array}{c}\text { Tsambel } \\
\text { "Back" }\end{array}$ & on (release)\{prevFrame0;\} & Sebelumnya & Sesuai \\
\hline $\begin{array}{c}\text { Tombel } \\
\text { "Menu" }\end{array}$ & $\begin{array}{c}\text { on } \\
\text { (release) (gotoAndStop("Menu"); }\end{array}$ & Menu Utama & Sesuai \\
\hline $\begin{array}{c}\text { Tombel } \\
\text { "Nexf" }\end{array}$ & on (release)\{nextFrame0;\} & Selanjumya & Sesuaj \\
\hline
\end{tabular}


Tabel 8

Hasil Pengujian Black Box Testing Halaman Menu Angka

\begin{tabular}{|c|c|c|c|}
\hline Input/Event & Proses & $\begin{array}{l}\text { Output/Next } \\
\text { Stage }\end{array}$ & $\begin{array}{c}\text { Easil } \\
\text { Pengujian }\end{array}$ \\
\hline $\begin{array}{l}\text { Tombel } \\
\text { "Suara" }\end{array}$ & on(release) \{gotoAndPlay(51);\} & $\begin{array}{l}\text { Mendengarka } \\
\text { bunyi anglka }\end{array}$ & Sesuaj \\
\hline $\begin{array}{l}\text { Tembol } \\
\text { "Tulis" }\end{array}$ & on(release) $\{$ gotoAndPlay $(1) ;\}$ & $\begin{array}{l}\text { Untuk melihat } \\
\text { cara penulisan } \\
\text { angka }\end{array}$ & Sesuaj \\
\hline Tombol & on (release) \{prevFrame();\} & Sebelumnya & SesLaj \\
\hline $\begin{array}{l}\text { Tembel } \\
\text { "Menu" }\end{array}$ & $\begin{array}{c}\text { on } \\
\text { (release) }\{\text { gotoAndStop ("Menu'); }\end{array}$ & Menu Utama & Sesuaj \\
\hline Tombel & on (release) \{nextr rame(); $\}$ & Selanjumya & Sesuaj \\
\hline
\end{tabular}

Tabel 9

Hasil Pengujian Black Box Testing Halaman Menu Keluar

\begin{tabular}{|c|c|c|c|}
\hline $\begin{array}{c}\text { Inpet/Ev } \\
e n t\end{array}$ & Proses & $\begin{array}{c}\text { Output } \\
\text { Neat } \\
\text { Stage }\end{array}$ & \begin{tabular}{|c|} 
Hassil \\
Penguj \\
inn
\end{tabular} \\
\hline \begin{tabular}{|l|} 
Tombol \\
"Skxasa"
\end{tabular} & on (release) \{gotoAndStop("Sxyara"); & $\begin{array}{l}\text { Menu } \\
\text { Sexass }\end{array}$ & \begin{tabular}{|l|l|} 
Sesuaji \\
\end{tabular} \\
\hline $\begin{array}{c}\text { Tombol } \\
\text { "Ngalage } \\
\text { na" } \\
\end{array}$ & on(release) (gotoAndStop("Ngalagena"); & $\begin{array}{c}\text { Menu } \\
\text { Ngalagena }\end{array}$ & \begin{tabular}{|l|l|} 
Sesuai \\
\end{tabular} \\
\hline \begin{tabular}{|c|} 
Tombol \\
"Rarang \\
ken"
\end{tabular} & on(release $)$ (gotoAndStop("Rarangken"); & \begin{tabular}{|c|} 
Meru \\
Rarangken
\end{tabular} & \begin{tabular}{|l|l} 
Sesuai \\
\end{tabular} \\
\hline $\begin{array}{l}\text { Tombol } \\
\text { "Angka" }\end{array}$ & on(release) (gotoAndStop("Angka"); & $\begin{array}{l}\text { Menu } \\
\text { Angka }\end{array}$ & \begin{tabular}{|l|l|} 
Sesuai \\
\end{tabular} \\
\hline $\begin{array}{c}\text { Tombol } \\
\text { "Permain } \\
\mathbf{a n}^{2}\end{array}$ & on(release) \{gotoAndStop("Permainan"); & $\begin{array}{c}\text { Menu } \\
\text { Permainan }\end{array}$ & \begin{tabular}{|l|l|} 
Sesuai \\
\end{tabular} \\
\hline \begin{tabular}{|l|} 
Tombol \\
"Profil1" \\
\end{tabular} & on(telease) $\{$ gotoAndStop("Profil"); & $\begin{array}{l}\text { Menu } \\
\text { Profin }\end{array}$ & \begin{tabular}{|l|l|} 
Sesuai \\
\end{tabular} \\
\hline $\begin{array}{l}\text { Tombol } \\
\text { "Keluar" }\end{array}$ & $\begin{array}{l}\text { on(release) \{mdm Application exit("ask"," "Apakah } \\
\text { Anda yakin ingin keluar?")\} Anda yakin ingin } \\
\text { keluar?")\} }\end{array}$ & $\begin{array}{l}\text { Memu } \\
\text { Keluar }\end{array}$ & \begin{tabular}{|l|l|} 
Sesuai \\
\end{tabular} \\
\hline
\end{tabular}

\section{PENUTUP}

\section{Kesimpulan}

Aksara Sunda yang merupakan warisan kebudayaan yang bernilai tinggi ini membutuhkan upaya pelestarian yang berkesinambungan dan mampu membuat masyarakat tertarik. Melalui animasi interaktif aksara Sunda ini, maka peluang untuk melestarikan kembali aksara Sunda kepada generasi muda nampaknya cukup kuat. Perlu adanya dukungan dari berbagai pihak untuk membantu agar animasi interaktif ini semakin dikenal dan diminati.

Animasi Interaktif Pengenalan Aksara Sunda ini diharapkan dapat digunakan oleh semua kalangan. Tampilan audio dan visual Animasi Interaktif Pengenalan Aksara Sunda dapat memberikan kemudahan dan daya tarik serta kelancaran dalam proses mensosialisasikan aksara Sunda.

\section{Saran}

Agar Aplikasi yang dibuat dapat digunakan lebih optimal dan dapat berjalan sesuai dengan yang diharapkan, maka ada beberapa saran yang dapat dijadikan bahan pertimbangan:

1. Gunakan spesifikasi komputer yang cukup guna kelancaran jalannya program.

2. Jika spesifikasi komputer yang digunakan kurang memadai, di sarankan untuk mengatur kualitas gambar pada program menjadi "low".

3. Perkembangan sistem operasi komputer menyebabkan Animasi Interaktif Pengenalan Aksara Sunda ini harus disesuaikan sehingga kompatibel pada perangkat yang digunakan.

4. Membuat Back Up data untuk menghindari hilangnya data secara tiba-tiba.

5. Untuk perkembangan selanjutnya perlu adanya tool yang mampu menterjemahkan huruf latin ke dalam aksara Sunda.

\section{REFERENSI}

Binanto, Iwan. 2010. Multimedia Digital Dasar Teorit Pengembangannya. Yogyakarta: Andi.

Black, Rex. 2007. Pragmatic Software Testing: Becoming an Effective Test Professional. Hoboken: Wiley Publishing Inc.

Ian, Sommerville. 2007. Software Engineering, Eight Edition. Harlow: Pearson Edication Limited.

Ladjamudin, Al Bahra bin. 2005. Analisa dan Disain Sistem Informasi. Yogyakarta: Graha Ilmu.

Madcoms. 2012. Kupas Tuntas Adobe Flash Professional CS6. Yogyakarta: Andi.

Munir. 2012.Multimedia Konsep dan Aplikasi dalam Pendidikan. Bandung: Alfabeta.

Purwacaraka, Pandan P. 2007. Cepat dan Mudah Home Recording dengan Adobe Audition 1.5. Yogyakarta: Andi.

Shukri Ahmad, Mohd. Naim dan Amran Md.Rasli .2006. Pengurusan Teknologi Jakarta: MTA.

Simarmata, Janner. 2010. Rekayasa Perangkat lunak. Yogyakarta: Andi.

Srinivas, Nidhra dan Jagruthl, Dondeti. 2012. Black Box and White Box Testing Techniques- A Literature Review. International Journal of Embedded Systems and Aplications (IJESA),2(2),12.

Syarif, Arry Maulana, Diginovac.2005. Tip dan Trik Membuat Fitur Game Flash.Jakarta: Elex Media Komputindo.

Tian J. 2007. Software Quality Engineering: Testing, Quality Assurance and 
Jurnal Informatika. Vol. I No. 2 September 2014

Quantifble Improvement.Hoboken: Jhon Wiley\& Sons Inc.

Tim Unicode Aksara Sunda. 2008. Direktori

Aksara Sunda untuk Unicode jilid

1.Bandung: Pemerintah Provinsi Jawa Barat Dinas Pendidikan Provinsi Jawa Barat. 